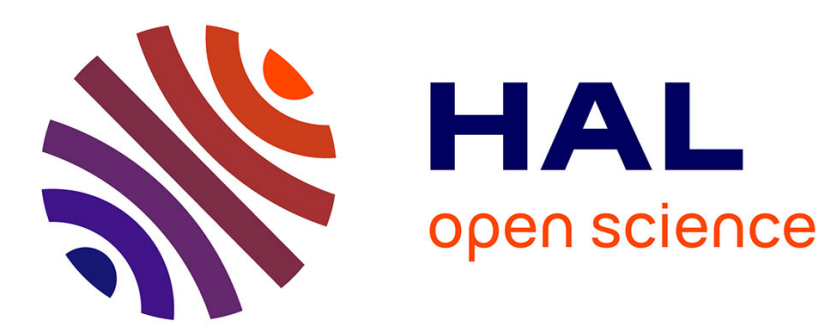

\title{
Towards a coupled heating-forming simulation of the thermoforming of thermoplastic composites
}

Theo Baumard, Gary H. Menary, Olivier de Almeida, Fabrice Schmidt, Peter Martin, Jérôme Bikard

\section{- To cite this version:}

Theo Baumard, Gary H. Menary, Olivier de Almeida, Fabrice Schmidt, Peter Martin, et al.. Towards a coupled heating-forming simulation of the thermoforming of thermoplastic composites. ESAFORM 2017 - 20h International ESAFORM conference on Material Forming, Apr 2017, Dublin, France. 10.1063/1.5008022 . hal-01629284v2

\section{HAL Id: hal-01629284 \\ https://hal.science/hal-01629284v2}

Submitted on 4 May 2018

HAL is a multi-disciplinary open access archive for the deposit and dissemination of scientific research documents, whether they are published or not. The documents may come from teaching and research institutions in France or abroad, or from public or private research centers.
L'archive ouverte pluridisciplinaire HAL, est destinée au dépôt et à la diffusion de documents scientifiques de niveau recherche, publiés ou non, émanant des établissements d'enseignement et de recherche français ou étrangers, des laboratoires publics ou privés. 


\title{
Towards a Coupled Heating-Forming Simulation of the Thermoforming of Thermoplastic Composites
}

\author{
Théo Baumard ${ }^{1,2, a)}$, Gary Menary ${ }^{1, \text { b) }}$, Olivier de Almeida $^{2, c)}$, Fabrice Schmidt ${ }^{2, \text { d) }}$, \\ Peter Martin ${ }^{1, e)}$ and Jérôme Bikard ${ }^{3}$ \\ ${ }^{1}$ School of Mechanical and Aerospace Engineering, Queen's University Belfast ; Ashby Building, Stranmillis Road, \\ Belfast BT9 5AH, United Kingdom \\ ${ }^{2}$ Université de Toulouse ; CNRS, Mines Albi, INSA, UPS, ISAE ; ICA (Institut Clément Ader) ; Campus Jarlard, \\ Route de Teillet, 81013 Albi, France \\ ${ }^{3}$ Solvay R\&I, Centre de Recherche et Innovation de Lyon ; 87, rue des Frères Perret, 69192 Saint-Fons, France \\ a) tbaumard01@qub.ac.uk \\ b) Corresponding author: g.menary@qub.ac.uk \\ c) olivier.dealmeida@mines-albi.fr \\ d) fabrice.schmidt@mines-albi.fr \\ e) p.j.martin@qub.ac.uk
}

\begin{abstract}
A strategy for the simulation of the whole thermoforming process, from the infrared heating to the stamping, is presented here. Two loosely coupled simulation tools are being developed: the first one computes a realistic 3D, transient temperature field of the composite stack inside an infrared oven, considering the radiative, conductive and convective heat transfers; the temperature distribution is used as an input for the second that aims at simulating the thermomechanical behaviour of the composite during the forming step via a non-orthogonal constitutive model. The steps for the identification of the model parameters are introduced. Initial validation tests show realistic results in term of shear angle distribution.
\end{abstract}

\section{INTRODUCTION}

The use of thermoplastic composites in the automobile sector was up until recently limited to non-structural parts or low volume, high-end vehicles. With new $\mathrm{CO}_{2}$ emissions regulations coming into effect by 2020 [1], their lightweightness and shorter manufacturing time achievable compared to thermosetting composites makes them interesting as possible replacement for metal in high volume applications. In order to efficiently reduce the costs associated with the new tooling design and ensure the quality of the parts produced, virtual manufacturing tools must be used to predict the optimal process parameters [2].
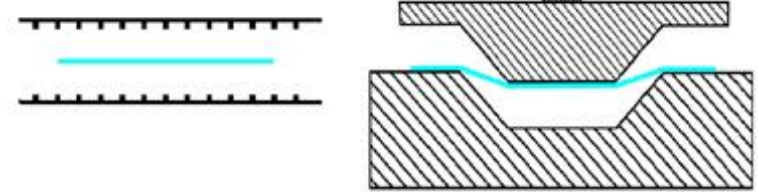

(a)

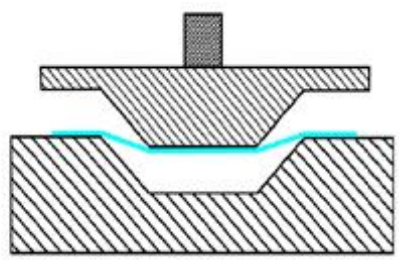

(b)

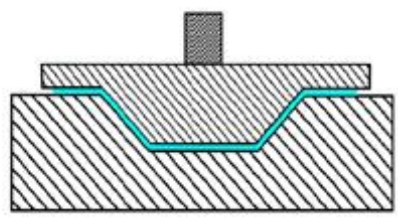

(c)

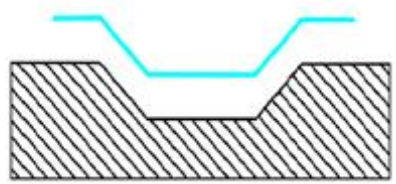

(d)

Figure 1 - Thermoforming process steps: (a) infrared heating, (b)-(c) forming and consolidation, (d) demoulding 
The thermoforming process consists in heating a laminate above the melting temperature of the thermoplastic matrix in an oven; it is then transferred to a press where it is formed and cooled down before demoulding. The sequential steps are presented in Figure 1. Originally developed for thermoplastic sheets, it is now used for manufacturing thermoplastic composites parts as high production volumes are in demand.

The field of forming simulation for woven composites has seen a lot of activity over the last years. While most of the effort is focused on developing constitutive models to represent the behaviour of the dry fabric during draping [3], it has been evidenced in recent studies that the forming cannot be considered adiabatic: when the laminate contacts the tool, its temperature rapidly decreases which can lead to local rigidification and formation of wrinkles. The thermomechanical models proposed thus far are either isothermal [4] or assume an homogeneous temperature field in the blank at the beginning of the forming step [5], which is complex to achieve in practice given the low conductivity of the polymers.

In this paper, we present a more comprehensive approach for the simulation of the thermoforming of thermoplastic preimpregnated composites. Two numerical tools are being developed to simulate the preheating step and the forming step respectively. The temperature field resulting from the infrared heating simulation will be used as an input for the forming simulation.

\section{HEATING SIMULATION}

The first step of the thermoforming process aims at bringing the composite blank to a temperature above the melting point of the matrix suitable for forming $\left(295^{\circ} \mathrm{C}\right.$ in the case of the PA66 matrix) in an oven. Infrared oven are often favoured in industrial composite applications for their fast heat-up time and the good absorptivity of polymers in the infrared wavelength range. However, the low thermal conductivity of the thermoplastic matrix (between 0.2 and $\left.0.5 \mathrm{~W} \cdot \mathrm{m}^{-1} \cdot \mathrm{K}^{-1}[6]\right)$ coupled with the spatial configuration of the oven in terms of number of heating elements, distance to the blank etc., can lead to temperature gradients both in plane and through the thickness [7].

The aim of the heating simulation developed is then to predict a realistic three dimensional temperature distribution in the composite stack during the preheating stage, to be later used as an input of a forming simulation; this tool can also be used to optimize an oven configuration for a given processing temperature.

The simulation is developed with Comsol Multiphysics finite elements software, and solves the 3D heat equation in the composite stack:

$$
\rho C_{p} \frac{\partial T}{\partial t}=\nabla \cdot(\kappa \nabla T)+q_{R}+q_{c}
$$

Where $\mathrm{q}_{\mathrm{r}}$ and $\mathrm{q}_{\mathrm{v}}$ are the radiative source term and convective losses respectively. The lamps used in this study emit in the near infrared (with $95 \%$ of the energy radiated in the range $[0.6 \mu \mathrm{m}-6 \mu \mathrm{m}]$ at their nominal temperature of 2400K). Transmission experiments showed that both the prepreg material and consolidated plates can be considered opaque in this wavelength range; the radiative term is thus computed using a view factor method via hemicube projection, rather than a more computationally expensive ray tracing approach. The entire environment of the oven (lamps, reflectors and preform) is explicitly modelled. The surfaces that make up the enclosure are assumed to be opaque, diffuse and grey. The convective losses are considered via the determination of a constant convective transfer coefficient.

The modelisation of the lamps is based on the work of Monteix [8]: only the tungsten filament is modelled as a cylinder of equivalent diameter taking into account the emissive surface of the spires. The temperature dependent emissivity and input power-temperature relation are considered for the tungsten.

Solving this equation requires the determination of the thermal properties of the lamps and composite, both in its non-consolidated and consolidated state . The considered material is a glass fabric/polyamide 6.6 thermoplastic composite developed by Solvay. It is supplied as a twill $2 / 2$ woven fabric, powder-impregnated on both sides. Consolidated plates were manufactured using a in-house thermocompression machine.

This study was conducted at Institut Clément Ader, using a novel method based on infrared thermography and inverse analysis to identify the temperatures of the lamps and thermal conductivity tensor of the material [9]. This 
experimental setup also allowed to characterize the inter-ply thermal contact resistances in a non-consolidated composite stack.

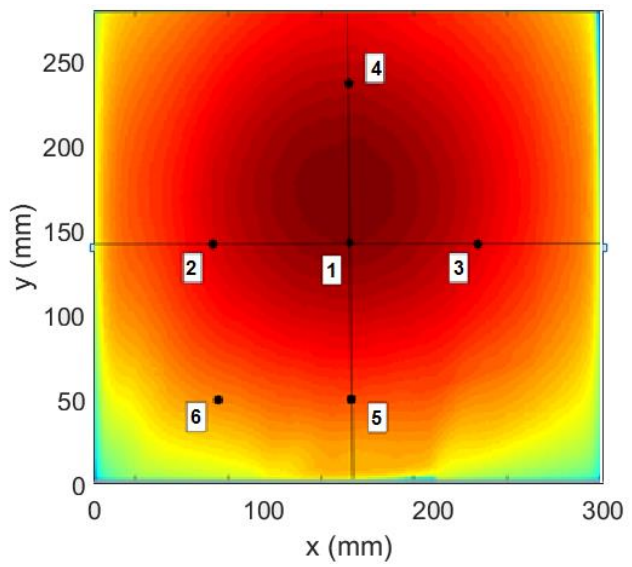

(a)

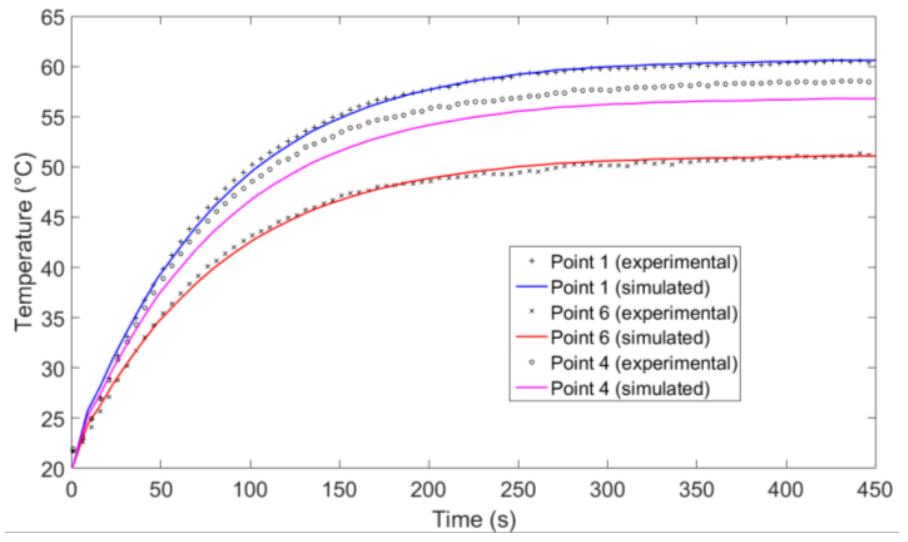

(b)

Figure 2 -(a) Temperature field on the backface of a [0/90]2s plate heated by a single lamp, (b) Comparison between experimental and simulated temperature

The results of a validation test case with a single lamp heating are presented in Figure 2. The temperature evolution is accurately predicted, with an underestimation of the temperature of the points lying in the convective plume, where the use of a constant heat transfer coefficient is not sufficient. Then, the ability of the model to optimize an infrared oven to minimize the temperature variation on a composite stack is investigated. An oven with 10 lamps disposed in two banks shifted by $4 \mathrm{~cm}$, with a center-to-center distance of $8 \mathrm{~cm}$ between each lamp in the same bank. The oven configuration, viewed from the top, is shown in Figure 3. On each bank (left and right), the lamps are numbered from the closest to the furthest of the plate symmetry axis.

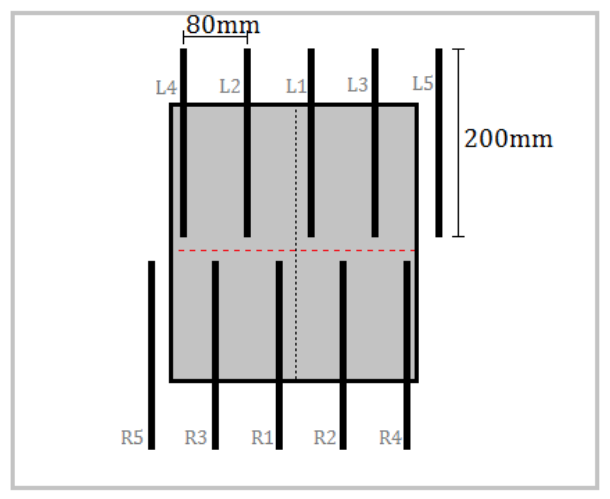

Figure 3 - Oven configuration

The composite stack is heated from the top only. In a first step, only the input power of the lamps is considered as a variable. The cost function to be minimized is therefore:

$$
\min _{20 \leq P_{i} \leq 100} f(\boldsymbol{P}), f(\boldsymbol{P})=\int_{V}\left(T(\boldsymbol{x})-T_{o b j}\right)^{2} d V
$$

With $\boldsymbol{P}$ a vector containing the individual input power values of the lamps. Given the symmetry of the oven, the dimension of $\boldsymbol{P}$ is reduced to 5 (i.e., $\mathrm{P}\left(\mathrm{L}_{\mathrm{i}}\right)=\mathrm{P}\left(\mathrm{R}_{\mathrm{i}}\right)$ ). The objective temperature is in this case $295^{\circ} \mathrm{C}$, which is approximately $30^{\circ}$ above the melting temperature of the thermoplastic matrix. Optimization is conducted in steadystate, using a Levenberg-Marquardt algorithm. The lamp input power is constrained between $20 \%$ and $100 \%$ of the 
nominal power to avoid under voltage. The temperature on the top of the composite stack along the red dotted line is shown in Figure 4 before and after the optimization procedure.

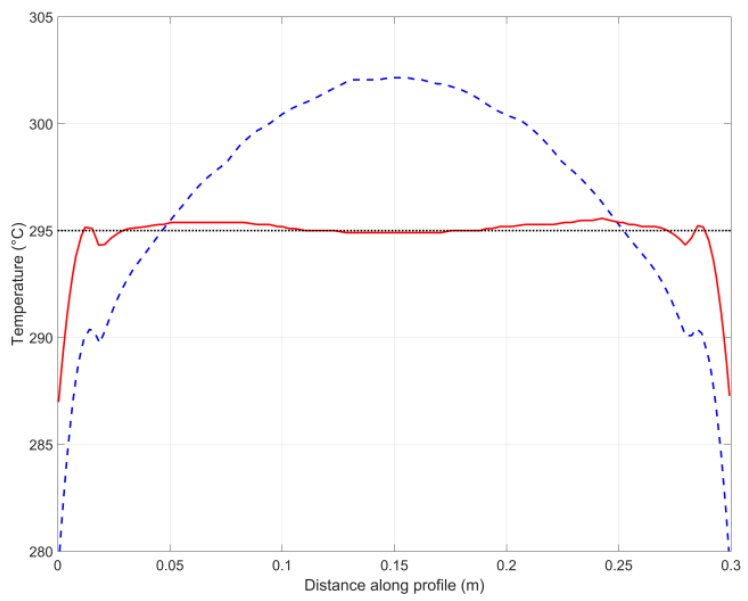

Figure 4 - Temperature along horizontal profile, dashed line: before optimization, solid line: optimized input power

The dashed blue line shows the temperature distribution along the profile with all lamps at the same input power (50\% of nominal power). The solid red line corresponds to the temperature field after optimization, and exhibits a much flatter profile: the central hot spot is avoided.

The transfer phase between the infrared oven and the mold and die in the actual process allows considering a loose coupling between the two simulation tools: the three dimensional temperature field that results from the heating simulation will be used as an input for the forming model.

\section{FORMING SIMULATION}

The forming simulation is based on a non-orthogonal constitutive model based on the work of Khan [10] and Pierce [11]. This model considers the composite as a continuous, anisotropic media, and tracks the orientation of the yarns, thus allowing the prediction of possible defect locations by visualizing the shear angle distribution in the part. This is done via a material user subroutine VUMAT implemented in Abaqus/Explicit. The subroutine works by calculating the fibre directions from the deformation gradient; the incremental strain is rotated from the GreenNaghdi frame used by Abaqus to the fibre frame; the incremental stress is computed in this frame from the constitutive law and converted back to the Green-Naghdi frame. The constitutive tensor assumes the following form in the fiber frame:

$$
C_{f}^{1}=\left[\begin{array}{ccc}
E_{1} & 0 & 0 \\
0 & 0 & 0 \\
0 & 0 & G_{12}
\end{array}\right], C_{f}^{2}=\left[\begin{array}{ccc}
0 & 0 & 0 \\
0 & E_{2} & 0 \\
0 & 0 & G_{12}
\end{array}\right]
$$

The superscripts 1, 2 represents the fiber directions, $E$ the Young's modulus and $G_{12}$ the shear modulus of the material. Tension-shear coupling and bending stiffness of the yarn are neglected. The advantages of this approach are the relative ease of implementation in commercial finite element codes, and the simplicity of the constitutive material tensor as the computation is conducted in the material frame.

A phenomenological, $3^{\text {rd }}$ order polynomial expression of the shear stress as a function of shear angle is derived from bias extension tests conducted on the dry fabric at ambient temperature, the resulting expression for the shear modulus being:

$$
G_{12}=a+2 b \cdot \gamma_{12}+3 c \cdot \gamma_{12}^{2}
$$

A bias extension test is simulated to validate this formulation. The resulting shear stress as a function of shear angle is plotted in Figure 5 against the experimental results from optical shear angle measurements. 


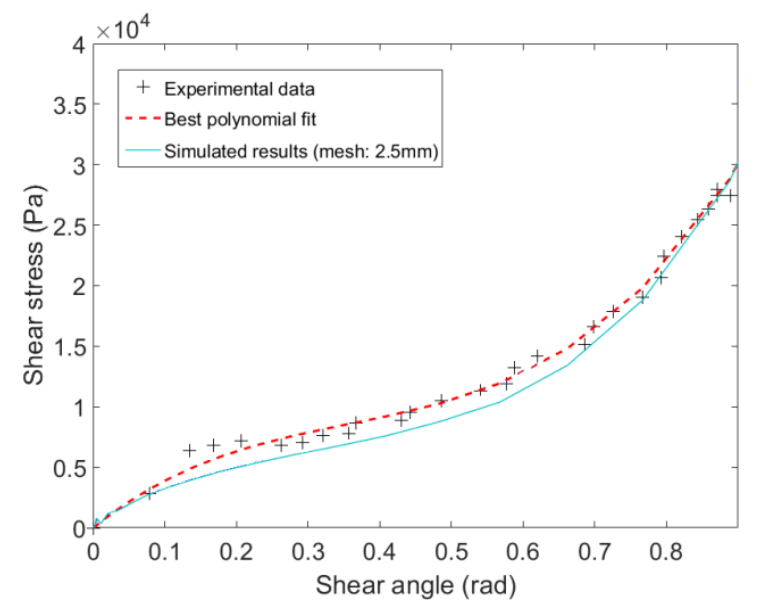

Figure 5 - Comparison between experimental and simulated bias extension tests on twill 2/2 dry fabric

The model, originally developed for draping simulations of dry fabric, is currently being extended to take into account the temperature dependent behaviour of the resin through its contribution to the shear modulus of the material. A bias extension campaign at high temperature and various strain rates is planned and experimental hemispherical punch apparatus is developed at Queen's University Belfast to validate the model formulation with stamping experiments. The fabric is held into place by the mean of a spring-actuated clamp to easily vary the clamping force, while the punch itself is mounted on a $60 \mathrm{kN}$ Promess press unit.

An example of the shape of the fabric after deformation by the punch is shown in Figure 6, with the camera direction aligned with the warp yarns. The first validation simulations (see Figure 7) show a good qualitative agreement with the experiments in terms of shear angle distribution and draw-in profiles, with the zones of maximum shear appearing at a $45^{\circ}$ angle from the principal fiber directions.

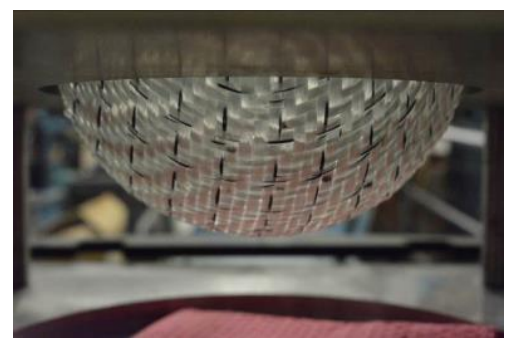

Figure 6- Hemispherical forming experiment on dry fabric
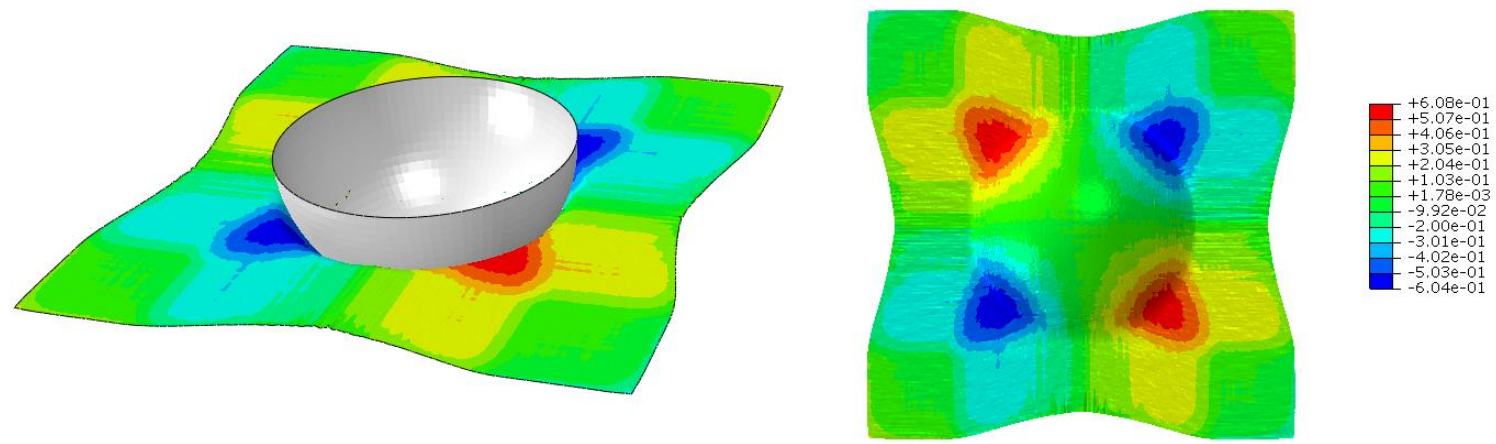

Figure 7 - Shear angle distribution after stamping, left: isometric view, right: bottom view 
The hemispherical punch will be used coupled with an infrared oven as a complete, instrumented lab-scale thermoforming setup to investigate the effect of temperature on the type and onset of defects generated.

\section{CONCLUSION}

Understanding the thermomechanical behaviour of thermoplastic composites during the thermoforming process is critical to accurately predict the defects that can appear during the manufacturing. In this article, the strategy for the development of a predictive, virtual manufacturing tool that relies on two coupled simulations of the infrared heating and forming steps has been presented. The material characterization procedure has been introduced for the thermophysical and mechanical properties, and is currently underway for high temperatures. The first validation test cases used for the simulations show the pertinence of the approach with promising qualitative results; these will be confirmed with the complete thermoforming setup being finalized.

\section{ACKNOWLEDGEMENTS}

The work was conducted at Institut Clément Ader, Ecole des Mines d'Albi and at the School of Mechanical and Aerospace Engineering, Queen's University Belfast. The authors would like to thank Solvay for supporting this study and providing the test materials.

\section{BIBLIOGRAPHY}

[1] International Council on Clean Transportation, "EU CO2 Emission standards for passenger cars and light commercial vehicles," 2014.

[2] W. B. Lee, C. F. Cheung and J. G. Li, "Applications of virtual manufacturing in materials processing," Journal of Materials Processing Technology, vol. 113, pp. 416-423, 2001.

[3] P. Boisse, R. Akkerman, J. Cao, J. Chen, S. Lomov and A. Long, "Composites Forming," in Advances in Material Forming, Springer Paris, 2007, pp. 61-79.

[4] M. Machado, M. Fischlschweiger and Z. Major, "A rate-dependent non-orthogonal constitutive model for describing shear behaviour of woven reinforced thermoplastic composites," Composites: Part A, vol. 80, pp. 194-203, 2016.

[5] E. Guzman-Maldonado, N. Hamila, N. Naouar, G. Moulin and P. Boisse, "Simulation of thermoplastic prepreg thermoforming based on a visco-hyperelastic model and a thermal homogenization," Materials and Design, vol. 93, pp. 431-442, 2016.

[6] Y. Yang, "Thermal conductivity," in Physical properties of polymers handbook, New York, Springer-Verlag, 2007, pp. 155-163.

[7] J. E. Cunningham, P. F. Monaghan, M. T. Brogan and S. F. Cassidy, "Modelling of pre-heating of flat panels prior to press forming," Composites: Part A, no. 28, pp. 17-24, 1997.

[8] S. Monteix, Modélisation du chauffage convecto-radiatif de préformes en PET pour la réalisation de corps creux, PhD thesis, Ecole des Mines de Paris, 2001.

[9] T. Baumard, O. De Almeida, G. Menary, Y. Le Maoult, F. Schmidt and J. Bikard, "Determination of thermal contact conductance in thermoplastic prepreg stacks using infrared thermography," in Proceedings of 19th ESAFORM conference, Nantes, 2016.

[10] M. Khan, T. Mabrouki, E. Vidal-Sallé and P. Boisse, "Numerical and experimental analyses of woven composite reinforcement forming using a hypoelastic behaviour," Journal of Materials Processing Technology, vol. 210, pp. 378-388, 2010.

[11] R. S. Pierce, B. G. Falzon, M. C. Thompson and R. Boman, "Implementation of a non-orthogonal constitutive model for the finite element simulation of textile composite draping," Journal of Applied Mechanics and Materials, vol. 553, pp. 76-81, 2014. 